\title{
Does alkali cation binding to aromatic ring retard the fluxional haptotropic migration? Evidences from density functional study
}

\author{
A KALPANA and L AKILANDESWARI* \\ Department of Chemistry, Sri Sarada College for Women (Autonomous), Salem, Tamil Nadu 636 016, India \\ E-mail: akilchem@gmail.com
}

MS received 24 July 2017; revised 23 September 2017; accepted 24 September 2017; published online 10 November 2017

\begin{abstract}
DFT calculations were performed on the sandwich complexes of naphthalene (MNC) with alkali metal cation $\left(\mathrm{Li}^{+} / \mathrm{Na}^{+} / \mathrm{K}^{+}\right)$on one $\pi$ face and the tripodal $\mathrm{Cr}(\mathrm{CO})_{3}$ moiety on the other with a view to explore the role of cation on haptotropic migration. Cation binding not only enhances the complex interaction energy but also delicately affects the fluxionality in the molecule by increasing the barrier to haptotropic shift of $\mathrm{Cr}(\mathrm{CO})_{3}$. The competing nature of the bifacial acids with sandwiched aromatic ring is established. In line with Pearson's HSAB principle, LiNC system with highest interaction energy is found to be the most stable one among all the systems under study.
\end{abstract}

Keywords. Cation- $\pi$ interactions; density functional theory; haptotropic rearragments; $\eta^{6}$-naphthalene- $\mathrm{Cr}(\mathrm{CO})_{3}$ complexes.

\section{Introduction}

The cation- $\pi$ interaction deserves to be called the most powerful interaction among the non-covalent interactions, and hence has wide range of applications in chemistry, material science and biology. ${ }^{1-5}$ Cation- $\pi$ interactions are electrostatic in origin and occurs when a cation interacts with the negatively charged $\pi$-electron cloud of an arene system. The strength of cation- $\pi$ interactions can be tuned over a long range by altering the factors such as nature of the cation and $\pi$ system, size of the $\pi$ system, nature of the substituents present in the $\pi$ system, etc., and it is this variability that underlies the utility of cation- $\pi$ interactions. ${ }^{5-7}$ Wide range of experimental and theoretical investigations have been reported on these cation interactions on many types of aromatic systems. ${ }^{5-10}$

$\eta^{6}$-arene- $\mathrm{Cr}(\mathrm{CO})_{3}$ systems are the most extensively studied half-sandwich complexes. ${ }^{11-19}$ Many experimental and theoretical investigations have extensively explored the conformational biasing, barrier to tripodal rotation, aromaticity, structural and energetics of such complexes. ${ }^{11-19}$ Exclusively, the $\pi$-complexes of polycyclic aromatics with metal moiety has the ability to undergo haptotropic rearrangements. There are two ways in which haptotropic rearrangements may

\footnotetext{
*For correspondence
}

proceed; (i) when the metal moiety changes its $\pi$ coordination to the arene ligand within the same ring (intra-ring haptotropic) and (ii) when it involves migration of metal moiety from one of the aromatic ring to the other (inter-ring haptotropic). ${ }^{20} \mathrm{In}$ an inter-ring haptotropic rearrangement (IRHR), the $\pi$-coordinated $\mathrm{ML}_{n}$-unit $(\mathrm{M}=$ metal, $\mathrm{L}=$ coligand) changes its connectivity by migrating between different rings of polycylic aromatics which is a ligand with multicoordinate site possibilities. ${ }^{21}$ Haptotropic shifts play significant role in transition metal catalysed processes and in designing organometallic switches. ${ }^{22,23}$ Exhaustive studies have been done on haptotropic shifts in complexes with aromatic polycyclic ligands, like naphthalene, anthracene where the metal ion moves across the rings. ${ }^{20,24-26}$ The simplest system in which haptotropic rearrangement takes place was $\eta^{6}$-naphthalene- $\mathrm{Cr}(\mathrm{CO})_{3}$ and its derivatives, which was first reported by Deubzer. ${ }^{27}$ Also, qualitative study on haptotropic rearragements in aromatic ligands with many transition metals such as Mo, $\mathrm{W}, \mathrm{Rh}, \mathrm{Pd}, \mathrm{Ir}, \mathrm{Ni}, \mathrm{Mn}, \mathrm{Fe}, \mathrm{Zr}, \mathrm{Ru}$ and $\mathrm{Os}$ have been reported. ${ }^{20}$ The mechanistic pathway for the metal moiety $\left[\mathrm{Cr}(\mathrm{CO})_{3}\right]$ migration in the naphthalene system was proposed by Albright et al. ${ }^{28}$ and they suggested that the metal-coligand unit migrates along the periphery of the naphthalene ligand with a $\mathrm{Cr}(\mathrm{CO})_{3}-\eta^{4}$-coordinated trimethylenemethane transition state complex, i.e., the $\mathrm{Cr}$ is approximately located above the $\mathrm{C} 2$ (or $\mathrm{C} 3$ ) atom rather than above the center of the $\mathrm{C} 2-\mathrm{C} 3$ bond (cf. 


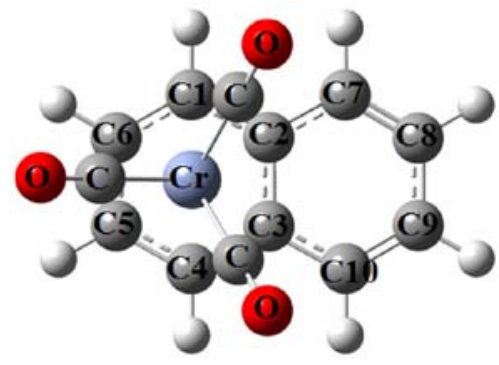

NC - Minima

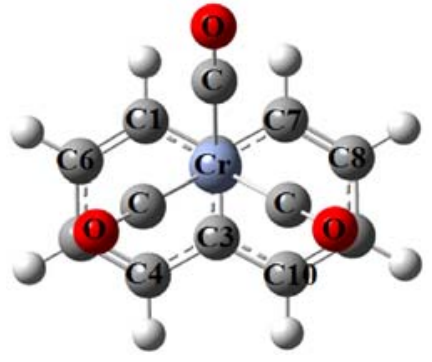

$\mathrm{NC}-\mathrm{Ts}$

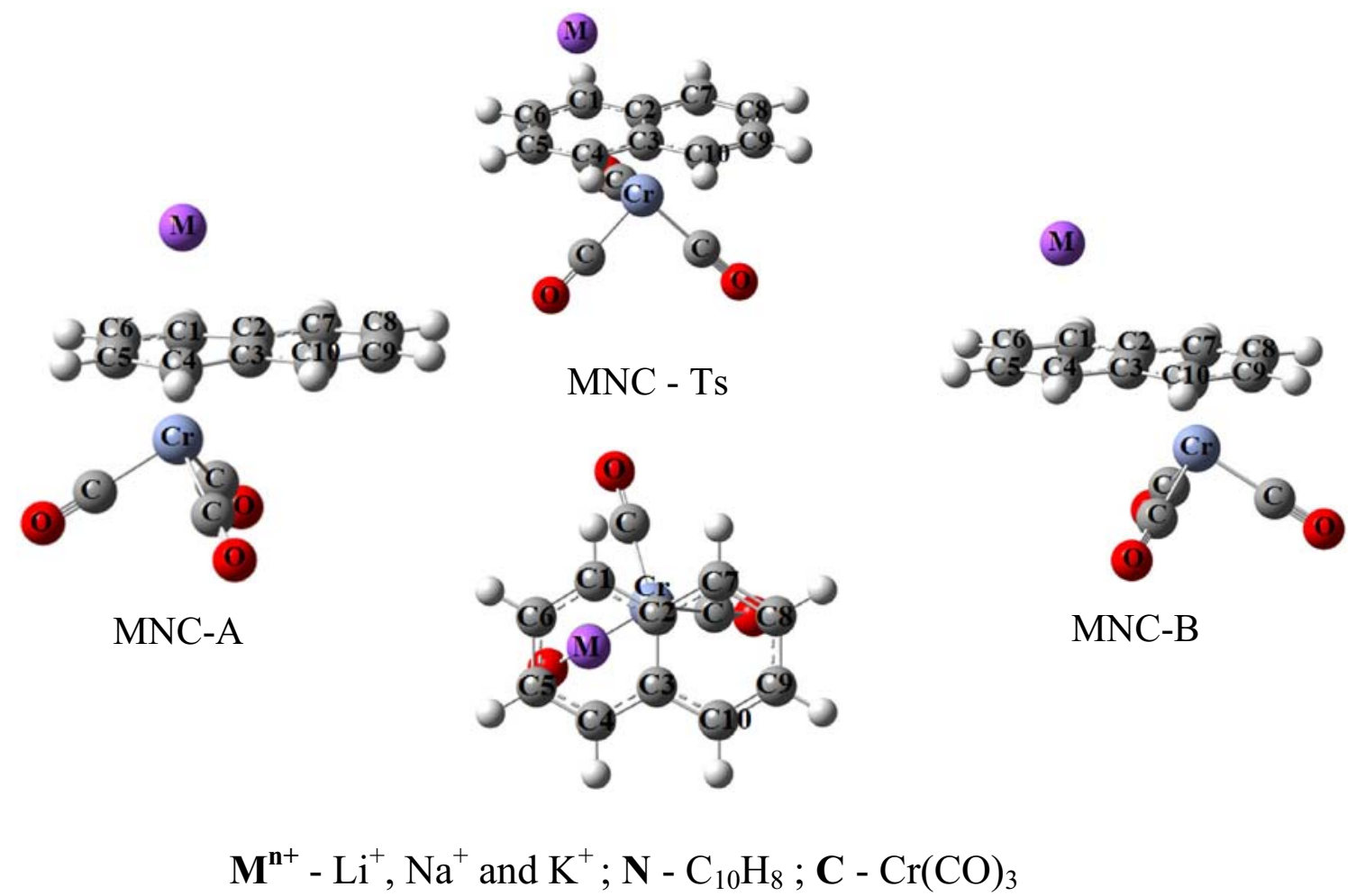

Figure 1. Geometry optimized structures of the $\mathrm{M}^{\mathrm{n}+}-\eta^{6}$-arene- $\mathrm{Cr}(\mathrm{CO})_{3}$ complexes.

Figure 1). Later, kinetic study of the $\eta^{6}-\eta^{6}$-haptotropic rearrangement in substituted naphthalene tricarbonyl chromium complexes have been reported. ${ }^{29-31}$ Further, many experimental and theoretical studies have documented the haptotropic rearrangement of $\mathrm{Cr}(\mathrm{CO})_{3} \mathrm{com}$ plexes with a variety of arenes. ${ }^{20-40}$ Molecular motion across the surfaces has significant importance in designing molecular machines such as molecular motors, brakes, switches, etc. and the past decade has been graced by a plethora of reports describing the design and function of such machines. ${ }^{41-43}$ Generally, the haptotropic migration can be influenced by the incorporation of redox-, photo- or $\mathrm{pH}$-sensitive functional groups in combination with a complementary substitution pattern in the metal moiety and the arene ligand and hence may facilitate the construction of a switchable device. ${ }^{23}$
And also, arene-chromium tricarbonyl compounds have attracted considerable attention for many years because of their potential applications in organic synthesis and in designing molecular switches/brakes, etc. ${ }^{41,43,44}$ In our previous theoretical work we have reported the structural and electronic effects of cation binding to $\pi$ system of $\eta^{6}$-benzene- $\mathrm{Cr}(\mathrm{CO})_{3} .{ }^{19}$ Although many factors that affect the haptotropicity have been reported to the best of our knowledge, effect of cation binding on the aromatic ring on the haptotropic energetics and stability have not been explored. We consider it is worth exploring because we have already reported that the cation binding modulates the stability of the sandwich complex involving the Pearson's Hard and Soft Acid Base (HSAB) concept. ${ }^{19}$ Therefore, assertively presuming the contribution of cation on fluxional haptotropic behaviour of $\mathrm{Cr}(\mathrm{CO})_{3}$ 
between the two rings of a simple naphthalene system bound to $\operatorname{Cr}(\mathrm{CO})_{3}$, we have intended to analyse the tuning effect of alkali metal cation on strength of the complexation energy, aromaticity, and most importantly on the fluxional behaviour of $\mathrm{Cr}(\mathrm{CO})_{3}$ moiety in $\eta^{6}$-naphthalene- $\mathrm{Cr}(\mathrm{CO})_{3}$ systems.

\section{Computational details}

All calculations have been performed with the GAUSSIAN09 program. ${ }^{45}$ Geometry optimizations was carried out at B3LYP ${ }^{46,47}$ method, 6-31G(d) basis set ${ }^{48}$ was used for carbon, oxygen, hydrogen atoms and metal ions $\left(\mathrm{Li}^{+}, \mathrm{Na}^{+}\right.$and $\mathrm{K}^{+}$). LANL2DZ basis set, ${ }^{49}$ was used for the chromium atom in $\mathrm{Cr}(\mathrm{CO})_{3}$. All the optimized structures were characterized by frequency analysis. The haptotropic transition state is located and characterized by single imaginary frequency along the normal mode of the desired haptotropic shift. The transition state has been connected with the reactants MNCA and B through IRC calculations. ${ }^{50}$ The interaction energies obtained were corrected for basis set superposition error (BSSE) using the counterpoise method described by Boys and Bernardi. ${ }^{51}$ Natural bond orbital analysis (NBO) ${ }^{52-54}$ and Nucleus-independent chemical shifts $\left(\mathrm{NICS}_{\mathrm{ZZ}}\right)^{55} \mathrm{calcu}-$ lations have been done by B3LYP method using 6-31G(d) basis set ${ }^{48}$ for carbon, oxygen, hydrogen atoms and metal ions $\left(\mathrm{Li}^{+}, \mathrm{Na}^{+}\right.$and $\left.\mathrm{K}^{+}\right)$and LANL2DZ basis set, ${ }^{49}$ for the chromium atom in $\mathrm{Cr}(\mathrm{CO})_{3}$. $\mathrm{NICS}_{\mathrm{zZ}}(0)$ was calculated at the geometrical centres of the ring atoms, and also $1 \AA$ above the ring $\mathrm{NICS}_{\mathrm{zz}}(1)$ using the gauge invariant atomic orbital (GIAO) $)^{56}$ method.

\section{Results and Discussion}

In the present study, the cation bound to the $\pi$ cloud of one aromatic ring of naphthalene which is bound to the tripodal $\mathrm{Cr}(\mathrm{CO})_{3}$ unit in $\eta^{6}$ fashion has been considered $\left[\mathrm{M}^{\mathrm{n}+}-\eta^{6}\right.$-naphthalene- $\mathrm{Cr}(\mathrm{CO})_{3}$ (MNC)] (Figure 1). Based on the location of the cation and $\mathrm{Cr}(\mathrm{CO})_{3}$ there can be two isomers - MNCA (both metal cation and $\mathrm{Cr}(\mathrm{CO})_{3}$ on the same ring) and MNCB (cation on one ring and $\mathrm{Cr}(\mathrm{CO})_{3}$ on the other) (Figure 1). These isomers are fortunately interconvertible through the haptotropic shift of $\mathrm{Cr}(\mathrm{CO})_{3}$ from one ring to another. The thermodynamic stability of the isomers MNCA and $\mathbf{B}$ are of interest since it would clarify the role of extended aromaticity in affecting the stability of the so called $\pi$ acid base interacting sandwich molecules (which has been explored in terms of role of cations in our earlier paper ${ }^{19}$ ). Also the subtle insights of role of cation$\pi$ interaction in influencing the fluxional haptotropic behaviour is studied by locating the haptotropic transition state (MNC-TS) (Figure 1). For the sake of comparison the MN (metal-cation bound naphthalene system) MB (metal-cation bound benzene system) analogues (without $\eta^{6}-\mathrm{Cr}(\mathrm{CO})_{3}$ ) and $\mathbf{M B C}$ (metal-cation bound $\eta^{6}-\mathrm{Cr}(\mathrm{CO})_{3}$-benzene system) have also been included. The geometries of the minima and TS are presented in Figure 1.

\subsection{Interaction energy}

The BSSE corrected interaction energy (IE) calculated for all the $\mathrm{M}^{\mathrm{n}+}$-naphthalene- $\mathrm{Cr}(\mathrm{CO})_{3}$ (MNC) systems under study are given in Table 1 . The Mulliken charges on different fragments (viz. metal-cation $\left(\mathrm{M}^{\mathrm{n}+}\right)$, ring $(\mathrm{R})$ and $\left.\mathrm{Cr}(\mathrm{CO})_{3}\right)$ are also presented in Table 1 . The thermodynamic stability of the two isomers (MNC$\mathrm{A}$ and MNC-B) could be compared by considering their interaction energies (Table 1). Although cation binding on the aromatic face of naphthalene- $\mathrm{Cr}(\mathrm{CO})_{3}$ system has sizeably altered their stability, it has very marginally differentiated MNCA and B by delicately stabilising B to A, immaterial of the metal ion. Now the prime intention of the paper is to focus on the role of cation on the stability of the isomers and on the haptotropic shift. The role of cations on the stability of the isomeric sandwich complexes are in line with HSAB (Hard and soft acid base) principle in which the aromatic cloud on one face acts as a hard base and consequently the stability is the highest for the hardest acid $\mathrm{M}=\mathrm{Li}^{+}$in MNCA and $\mathrm{B}$ and the trend goes as follows:

$$
\mathrm{Li}^{+}>\mathrm{Na}^{+}>\mathrm{K}^{+} \text {(in line with hard acid trend) }
$$

This is applicable for both the isomers. Yet another observation is that the interaction energies of all the MNCs are higher than their corresponding MN analogues. This is quite understandable as the former has two interactions with the $\pi$ cloud of the aromatic unit on both faces and the latter has only cation- $\pi$ interaction. But the magnitude of interaction is less than the additivity of their individual interactions $\left(\mathrm{IE}_{\mathrm{MNC}}<\mathrm{IE}_{\mathrm{MN}}+\right.$ $\mathrm{IE}_{\mathrm{NC}}$ ) (Table 1) signifying a competitive behaviour.

As this paper addresses the role of extended delocalisation, comparison of naphthalene systems with their corresponding benzene analogues is worth doing. The right end of the Table 1 presents the parameters for benzene analogues ${ }^{19}$ for comparison purpose. It shows that benzene systems of $\mathrm{Na}$ and $\mathrm{K}(\mathrm{NaBC}$ and $\mathrm{KBC})$ have slightly higher interaction energy than their corresponding naphthalene analogues ( $\mathrm{NaNC}$ and $\mathrm{KNC}$ ). For $\mathrm{Li}$, both naphthalene and benzene analogues have nearly equal energy. But it is worth noting that $\mathrm{MN}$ analogues are more stable than MB (increased interaction energy by nearly $2 \mathrm{kcal} / \mathrm{mol}$ ). This can be explained 


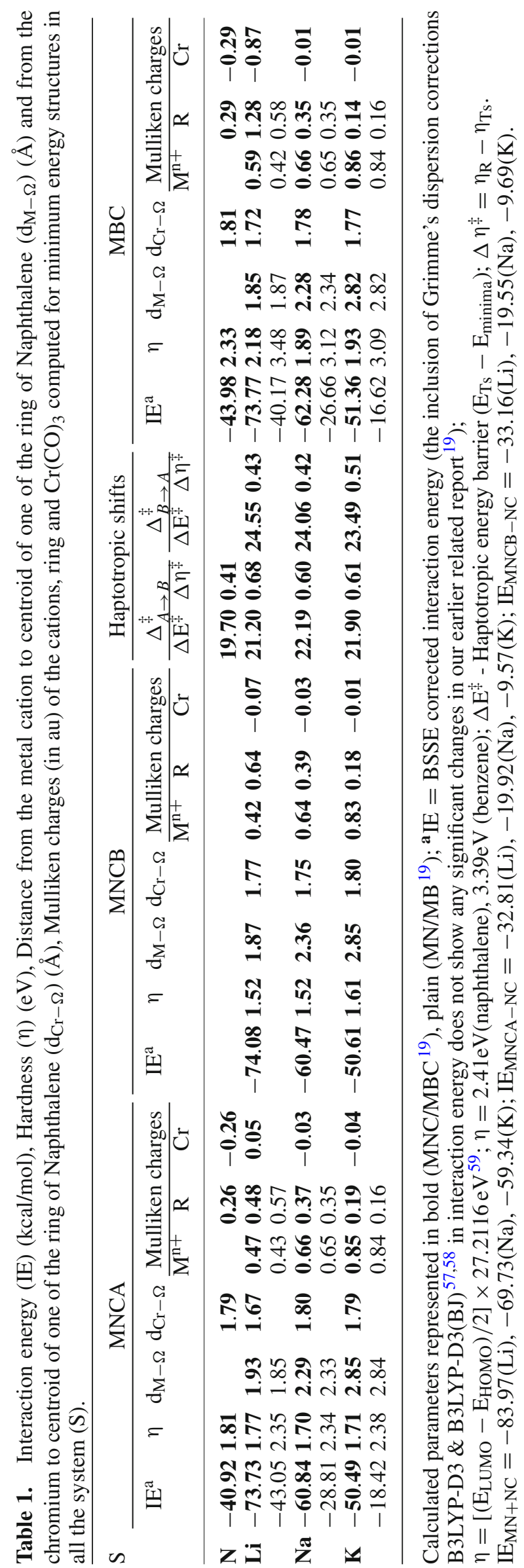


as follows: from the Mulliken charges (Table 1) it is found that both $\mathrm{MB}$ and $\mathrm{MN}$ carry nearly the same quantum of positive charge on metal and arene moiety but the stability of MN system could be attributed to the larger delocalisation of charges across both the rings of naphthalene in contrast to lesser delocalisation in benzene. Now revisiting the exactly reversed observation of MNC and MBC with the charge perspective, it is clear that in contrast to $\mathrm{MN}$ and $\mathrm{MB}$ cases the positive charge on aromatic moiety is increased due to the drain of electrons into $\mathrm{Cr}(\mathrm{CO})_{3}$. It is observed from the Table 1 that the $\mathrm{Cr}(\mathrm{CO})_{3}$ moiety has $(-0.03$ ( NaNC) and $-0.04(\mathrm{KNC}))$ units of electrons while it is just $(-0.01)$ in the case $\mathrm{NaBC} / \mathrm{KBC}$. The excess of positive charge on the naphthalene ring of NaNC and KNC than those of their benzene counterparts probably explains the observation that interaction energy of MNC is slightly lower than MBC in the case of $\mathrm{Na}$ and $\mathrm{K}$ systems. LiNC behaves differently and has to be focussed separately because, in contrast to the above statement that MNCA/B have lower interaction than their MBC counterparts by nearly $2 \mathrm{kcal} / \mathrm{mol}$, the LiNCA and B are almost equal LiBC. This can also be explained by looking at the charges on each moiety. In LiBC the positive charge on the ring is very high due to the transfer of electron to $\mathrm{Cr}(\mathrm{CO})_{3}$ but both LiNCA and $\mathrm{B}$ have much less positive charge on aromatic ring (+0.48 and 0.64 , respectively) than LiBC $(+1.28)$ (Table 1$)$. There is only a small difference between charge on $\mathrm{Cr}(\mathrm{CO})_{3}$ in LiNCA and $\mathrm{B}$. The former is slightly positive and the latter is slightly negative and probably this minuscule charge drain in the latter could have given a slightly more stability than the former and $\mathrm{LiBC}$ too!

\subsection{Reactivity}

The lower hardness values $(\eta)$ in the Table 1 reveals that the $\mathrm{MN}$ and $\mathrm{MNC}$ systems possess higher reactivity than their corresponding benzene counterparts (MB and $\mathrm{MBC})$. And also, $\mathrm{Cr}(\mathrm{CO})_{3}$ fragment present in $\mathrm{MNC}$, enhances their reactivity when compared to $\mathrm{MN}$ complexes (Table 1). Also MNCA is slightly harder than MNCB but their stability is reverse. This is similar to our earlier reports that cation binding increases the interaction energy and reduces the hardness making the molecule more susceptible for reaction.

\section{$3.3 d_{M-\Omega}$ and $d_{C r-\Omega}$}

From the Table 1, it is known that the $\mathrm{Li}^{+}$complexes have minimum cation- $\pi$ distance and maximum interaction energy among all MNC complexes. A slight

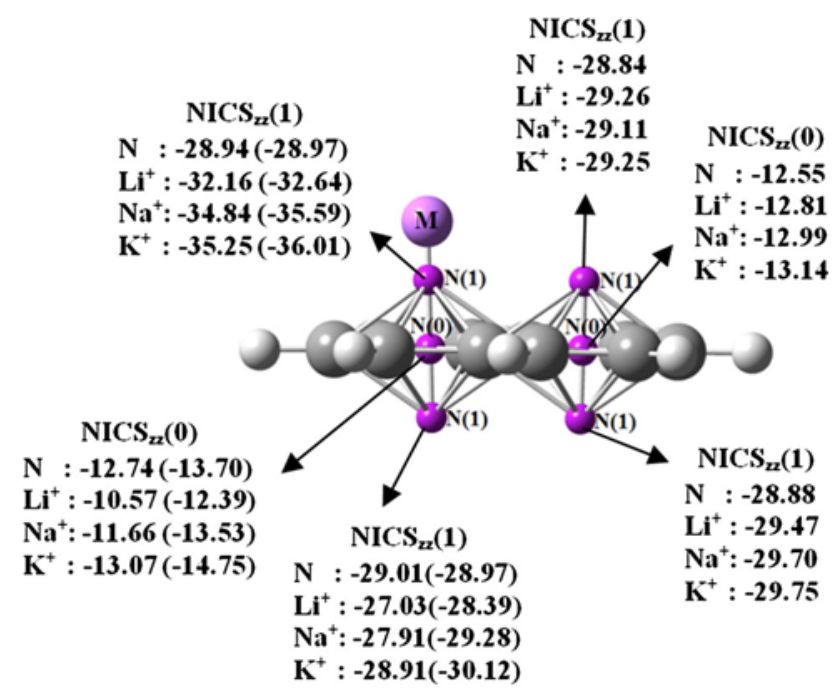

Figure 2. $\mathrm{NICS}_{\mathrm{Zz}}(0)$ and $\mathrm{NICS}_{\mathrm{Zz}}(1)$ (above and below the plane) values of MN (corresponding $\operatorname{NICS}_{\mathrm{Zz}}(0)$ and $\mathrm{NICS}_{\mathrm{ZZ}}$ (1) values of benzene counterparts are shown in bracket).

decrease in $\mathrm{M}-\Omega$ distance of $\mathrm{MN}$ compared to $\mathrm{MB}$, accounts for the slight higher interaction energy of the former. As the size of the $\pi$-system increases from MBC to MNC, the M- $\Omega$ distance slightly increases in MNC systems, and it indicates the competitive interactions between the two acids (viz., metal cation and $\mathrm{Cr}(\mathrm{CO})_{3}$ ) with the common $\pi$-base (naphthalene ring). However, the perturbation of $\mathrm{Cr}-\pi /$ cation- $\pi$ distances in $\mathrm{MNC}$ compared $\mathrm{MN} / \mathrm{NC}$ systems were not in accordance with their corresponding IE trend. Thus cation- $\pi$ and $\mathrm{Cr}-\pi$ distance may not be the most appropriate structural parameters for determining the strength of binding of metal cation/Cr moiety. ${ }^{10}$

\subsection{Aromaticity}

The computed $\mathrm{NICS}_{\mathrm{zz}}(0)$ and $\mathrm{NICS}_{\mathrm{zz}}(1)^{15}$ values of the cation bound naphthalene (MN) and cation bound naphthalene - chromium tricarbonyl complexes (MNCA and MNCB) are presented in Figures 2, 3 and 4, respectively. The $\mathrm{NICS}_{\mathrm{zz}}(0)$ and $\mathrm{NICS}_{\mathrm{zz}}(1)$ values of their corresponding benzene counterparts are also shown in Figures 2, 3 and 4 (in brackets), respectively, for the comparison purpose.

3.4a Effect of size of $\pi$-system on aromaticity: As the size of the $\pi$-system increases from metal cation bound benzene (MB) to metal cation bound naphthalene $(\mathrm{MN})$ system (Figure 2) or from metal cation bound benzene-chromium tricarbonyl (MBC) to metal cation bound naphthalene-chromium tricarbonyl (MNCA and B) systems (Figures 3 and 4), both the $\mathrm{NICS}_{\mathrm{zz}}(0)$ and (1) decreases. 


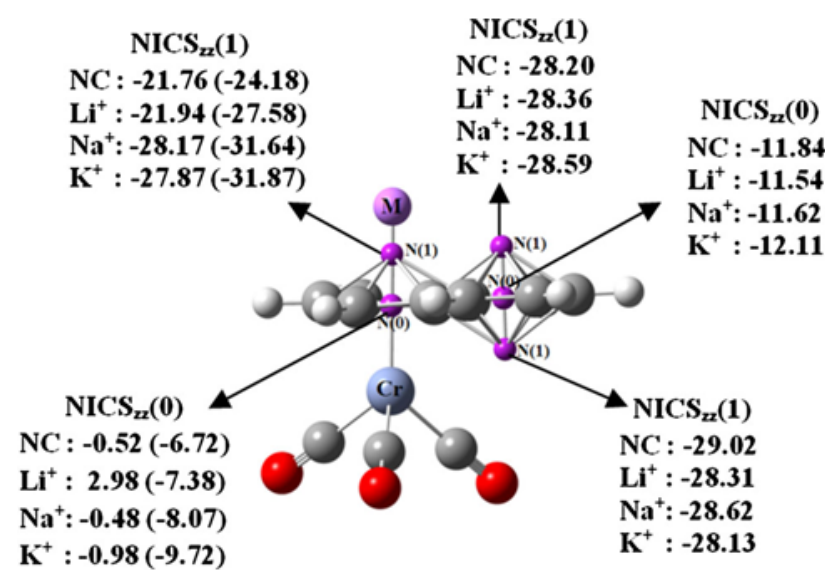

Figure 3. $\mathrm{NICS}_{\mathrm{zz}}(0)$ and $\mathrm{NICS}_{\mathrm{zz}}(1)$ (above and below the plane) values of MNCA (corresponding $\operatorname{NICS}_{\mathrm{Zz}}(0)$ and $\mathrm{NICS}_{\mathrm{Zz}}$ (1) values of benzene counterparts are shown in bracket).

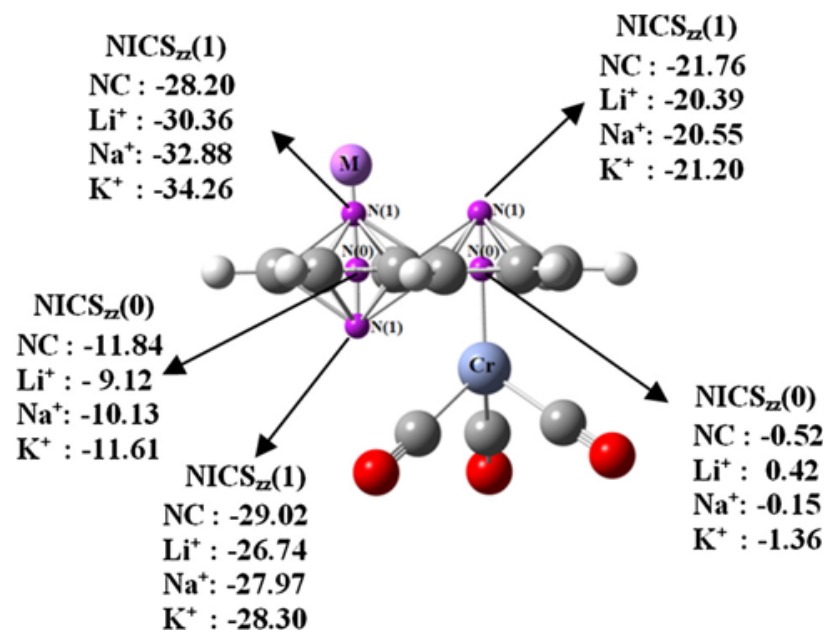

Figure 4. $\operatorname{NICS}_{\mathrm{zz}}(0)$ and $\mathrm{NICS}_{\mathrm{zz}}(1)$ (above and below the plane) values of $\mathrm{MNCB}$ (corresponding $\operatorname{NICS}_{\mathrm{ZZ}}(0)$ and $\mathrm{NICS}_{\mathrm{ZZ}}$ (1) values of benzene counterparts are shown in bracket).

3.4b Effect of $\mathrm{Cr}(\mathrm{CO})_{3}$ on aromaticity: The effect of $\mathrm{Cr}(\mathrm{CO})_{3}$ moiety could be observed by comparing the $\mathrm{NICS}_{\mathrm{zz}}$ values of simple naphthalene $(\mathrm{N})$ with that of naphthalene-chromium tricarbonyl (NC) and metal cation bound naphthalene $(\mathrm{MN})$ with that of metal cation bound naphthalene-chromium (MNCA and B) (Figure 2 with Figures 3 and 4) and it is inferred that the coordination of $\mathrm{Cr}(\mathrm{CO})_{3}$ fragment to naphthalene or metal bound naphthalene system would reduce both $\operatorname{NICS}_{\mathrm{zz}}(0)$ and (1) aromaticity.

3.4c Effect of metal cation on aromaticity: The role of metal cation on aromaticity could be observed by comparing the $\mathrm{NICS}_{\mathrm{zz}}$ values of simple naphthalene (N) with that of metal bound naphthalene system (MN) (Figure 2) and naphthalene-chromium tricarbonyl (NC) with that of metal bound naphthalene-chromium tricarbonyl (MNCA and B) (Figures 2 and 3). The binding of metal cation to naphthalene or naphthalene-chromium system reduces the $\mathrm{NICS}_{z \mathrm{z}}(0)$ aromaticity but increases $\mathrm{NICS}_{\mathrm{zz}}(1)$ aromaticity of the particular ring to which it is bound in naphthalene of MN and MNC systems.

\subsection{Effect of cation on haptotropic shift}

Cation interaction with both rings of naphthalene$\mathrm{Cr}(\mathrm{CO})_{3}$ yields two isomers $\mathrm{A}$ and $\mathrm{B}$ which are interconvertible by the haptotropic shift of $\mathrm{Cr}(\mathrm{CO})_{3}$ from one ring to another. It is clear from the Table 1 that the barrier to haptotropic shift has increased upon cation binding in general. Especially the barrier to convert $\mathrm{B}$ to $\mathrm{A}$ is around $2 \mathrm{kcal} / \mathrm{mol}$ higher lying than that for A to B interconversion. This establishes that the thermodynamic and kinetic stability go hand in hand with one another. A noteworthy observation is that unanimously all the cations exert same effect on haptotropic shift of $\mathrm{Cr}(\mathrm{CO})_{3}$ and thereby there is no differentiating effect which can be related to hard acid (Pearson's concept) as has been discussed for interaction energy. The activation hardness presented in Table 1 shows that cation binding has increased the $\Delta \eta^{\ddagger}$ and it is in line with the observed haptotropic barrier (especially $\Delta_{A \rightarrow B}^{\ddagger}$ than $\Delta_{B \rightarrow A}^{\ddagger}$ ). This signifies that haptotropic event is Frontier orbital controlled. Therefore, the barrier enhancement during fluxional haptotropicity may be considered as an immediate effect of cations on Frontier orbitals. Frontier orbital energies listed in the Table 2 show that HOMO and LUMO of cation bound naphthalene chromium

Table 2. Energy of Frontier molecular orbitals (HOMO and LUMO) in atomic units computed for all the systems under study.

\begin{tabular}{lcc}
\hline System & HOMO & LUMO \\
\hline NC & -0.201 & -0.068 \\
NC-TS & -0.192 & -0.089 \\
N & -0.212 & -0.035 \\
LiNCA & -0.340 & -0.210 \\
LiNCB & -0.334 & -0.222 \\
LiNC-TS & -0.319 & -0.239 \\
LiN & -0.384 & -0.211 \\
NaNCA & -0.328 & -0.203 \\
NaNCB & -0.321 & -0.209 \\
NaNC-TS & -0.306 & -0.225 \\
NaN & -0.367 & -0.195 \\
KNCA & -0.315 & -0.189 \\
KNCB & -0.310 & -0.192 \\
KNC-TS & -0.294 & -0.213 \\
KN & -0.354 & -0.179 \\
\hline
\end{tabular}


tricarbonyl complexes and their transition states are stabilised than their counterparts without cations. Therefore during this dynamic haptotropicity the role of cation is clearly that of any unit positive charge depreciating the electron density of the aromatic ring and thereby imparts a large barrier to the fluxional shift than the ones without cation binding.

\section{Conclusions}

Cation- $\pi$ interaction with the fused aromatic ring system, $\eta^{6}$-naphthalene- $\mathrm{Cr}(\mathrm{CO})_{3}$ has enhanced both the interaction energy and reactivity (decreased hardness). The interaction energy is linearly related to Pearson's hard acid nature of the binding cation, with LiNC having maximum interaction energy. But the interaction between the bifacial acids $\left(v i z . \mathrm{M}^{\mathrm{n}+}\right.$ on one face and $\mathrm{Cr}(\mathrm{CO})_{3}$ on the other) towards the sandwiched aromatic naphthalene unit is rather competitive than cooperative. Further the fluxional migration of $\mathrm{Cr}(\mathrm{CO})_{3}$ to both the ring centres become is less facile in the presence of cation in general and no specific differentiating influence is afforded by the alkali cations as in the case of interaction energies.

\section{Acknowledgements}

The authors thank Prof. P. Venuvanalingam, CSIR Emeritus Professor, School of Chemistry, Bharathidasan University, for his constant support and suggestions. The authors thank University Grants Commission, NewDelhi, for the financial assistance (Proposal Nos. F-MRP-5586/15; F-MRP6409/16(SERO/UGC)).

\section{References}

1. Dougherty D A 1996 Cation $-\pi$ interactions in chemistry and biology. A new view of benzene, Phe, Tyr, and Trp Science 271163

2. Mecozzi S, West A P Jr and Dougherty D A 1996 Cation$\pi$ interactions in simple aromatics: Electrostatics provide a predictive tool J. Am. Chem. Soc. 1182307

3. Zacharias N and Dougherty D A 2002 Cation-pi interactions in ligand recognition and catalysis Trends Pharmacol. Sci. 23281

4. Knowles R R and Jacobsen E N 2010 Attractive noncovalent interactions in asymmetric catalysis: Links between enzymes and small molecule catalysts Proc. Natl. Acad. Sci. USA 10720678

5. Mahadevi A S and Sastry G N 2013 Cation- $\pi$ interaction: Its role and relevance in chemistry, biology, and material science Chem. Rev. 1132100

6. Ma J C and Dougherty D A 1997 The cation $-\pi$ interaction Chem. Rev. 971303

7. Dougherty D A 2013 The cation $-\pi$ interaction Acc. Chem. Res. 46885
8. Frontera A, Quinonero D and Deyà P M 2011 Cation- $\pi$ and anion- $\pi$ interactions WIREs. Comput. Mol. Sci. 1 440

9. An Y and Wheeler S E 2015 Cation- $\pi$ interactions. In Encyclopedia of Inorganic and Bioinorganic Chemistry (USA: John Wiley) pp. 1-11

10. Vijay D and Sastry G N 2008 Exploring the size dependence of cyclic and acyclic $\pi$-systems on cation $-\pi$ binding Phys. Chem. Chem. Phys. 10582

11. Rosillo M, Dominguez G and Perez-Castells J 2007 Chromium arene complexes in organic synthesis Chem. Soc. Rev. 361589

12. Mutterties E L, Bleeke J R, Wuchere E J and Albright T A 1982 Structural, stereochemical, and electronic features of arene-metal complexes Chem. Rev. 82499

13. Low A A and Hall M B 2000 Benzene chromium tricarbonyl revisited: Theoretical study of the structure and dynamics of $\left(\eta^{6}-\mathrm{C}_{6} \mathrm{H}_{6}\right) \mathrm{Cr}(\mathrm{CO})_{3}$ Int. J .Quant. Chem. 77 152

14. Suresh C H, Koga N and Gadre S R 2000 Molecular electrostatic potential and electron density topography: Structure and reactivity of (substituted arene) $\mathrm{Cr}(\mathrm{CO})_{3}$ complexes Organometallics 193008

15. Feixas F, Jimenez-Halla J O C, Matito E, Poater J and Sola M 2007 Is the aromaticity of the benzene ring in the $\left(\eta^{6}-\mathrm{C}_{6} H_{6}\right) \mathrm{Cr}(\mathrm{CO})_{3}$ complex larger than that of the isolated benzene molecule? Polish J. Chem. 81 783

16. Kalpana A and Akilandeswari L 2015 The effect of fluorine substitution on the conformation and aromaticity of $\eta^{6}$-fluoro arene chromium tricarbonl complexes-Density functional insights Comput. Theor. Chem. 1069125

17. Kalpana A and Akilandeswari L 2016 Expensive tripodal rotation of $\eta^{6}$-chromium tricarbonyl complexes of phosphabenzene-Insights from DFT study Comput. Theor. Chem. 1084103

18. Kalpana A and Akilandeswari L 2017 Tuning the tripodal rotational barrier in $\eta^{6}$-chromiumtricarbonyl heteroarenes: A step towards torsional switches Ind. J. Chem. 56A 610

19. Kalpana A and Akilandeswari L 2017 Structural and electronic effects of cation binding $\left(\mathrm{Li}^{+}, \mathrm{Na}^{+}, \mathrm{K}^{+}, \mathrm{Mg}^{2+}\right.$ and $\mathrm{Ca}^{2+}$ ) to $\pi$ system of $\eta^{6}$-benzene- $\mathrm{Cr}(\mathrm{CO})_{3}$ complex: A theoretical study J. Serb. Chem. Soc. https://doi.org/ 10.2298/JSC161228063K

20. Oprunenko Y F 2000 Inter-ring haptotropic rearrangements in $\pi$ complexes of transition metals with polycyclic aromatic ligands Russ. Chem. Rev. 69683

21. Anh N T, Elian M and Hoffmann R 1978 Transits across a cyclopentadienyl. Organic and organometallic haptotropic shifts J. Am. Chem. Soc. 100110

22. Dötz K H, Wenzel B and Jahr H C 2004 Tunable haptotropic metal migration in fused arenes: Towards organometallic switches Chem. Rec. 461

23. Dötz K H, Wenzel B and Jahr H C 2005 ChromiumTemplated Benzannulation and Haptotropic Metal Migration Top. Curr. Chem. 24863

24. Arrais A, Diana E, Gervasio G, Gobetto R, Marabello D and Stanghellini P L 2004 Synthesis structural and spectroscopic characterization of four $\left[\left(\eta^{6}-\mathrm{PAH}\right) \mathrm{Cr}(\mathrm{CO})_{3}\right]$ complexes (PAH=Pyrene Perylene Chrysene 1,2Benanthracene) Eur. J. Inorg. Chem. 71505 
25. Stanger A 1991 Is the haptotropic rearrangement in bis(tributylphosphine) (anthracene) nickel inter- or intramolcular? Determinaiton of the molecularity by a spin saturation transfer Organometallics 102979

26. Dotz K H, Stendel J, Muller S, Neiger M, Ketrat S and Dolg M 2005 Haptotropic metal migration in density substituted hydroquinoid phenanthrene $\mathrm{Cr}(\mathrm{CO})_{3}$ complexes Organometallics $\mathbf{2 4} 3219$

27. Deubzer B 1966 Ph.D. thesis, Technische Hochschule München, Munich, Germany

28. Albright $\mathrm{T}$ A, Hofmann P, Hoffmann R, Lillya C P and Dobosh P A 1983 Haptotropic rearrangements of polyene- $\mathrm{ML}_{n}$ complexes. II. Bicyclic polyene-MCp, -M(CO) $)_{3}$ systems J. Am. Chem. Soc. 1053396

29. Kirss R U and Treichel P M 1986 Haptotropic rearragnments in naphthalene-chromium tricarbonyl complexes J. Am. Chem. Soc. 108853

30. Oprunenko Y F, Akhmedov N G, Laikov D N, Malyugina S G, Mstislavsky V I, Roznyatovsky V A, Ustynyuk Y A and Ustynyuk N A 1999 Regioselective synthesis of $\pi$-complexes of substituted polycyclic aromatic compounds. Experimental (NMR) and theoretical (DFT) studies of $\eta^{6}, \eta^{6}$-haptotropic rearragements in naphthalenechromiumtricarbonyl complexes J. Organomet. Chem. $\mathbf{5 8 3} 136$

31. Dötz K H, Stinner C and Nieger M 1995 Reactions of complex ligands. 67. Optically-active naphthalene$\mathrm{Cr}(\mathrm{CO})_{3}$ complexes via diastereoselective carbene annulation and haptotropic metal migration J. Chem. Soc. Chem. Commun. 2535

32. Kuendig E P, Desorby V, Grivet C, Rudolf B and Spichiger S 1987 Regioselective electrophilic substitution via lithiation and intramolecular arene exchange (haptotropic rearrangement) in (naphthalene)tricarbonylchromium Organometallics 6 1173

33. Ketrat S, Muller S and Dolg M 2007 A Quantum chemical study of the haptotropic rearrangements of $\mathrm{Cr}(\mathrm{CO})_{3}$ on naphthalene and phenanthrene systems $J$. Phys. Chem. A. 1116094

34. Turker L and Gumus S 2008 Ab initio and DFT studies on certain $\eta^{6}$-anthraquinone- $\mathrm{Cr}(\mathrm{CO})_{3}$ complexes Polycycl. Aromat. Compd. 28181

35. Turker L and Gumus S 2009 DFT studies of $\eta^{6}$ coronene- $\mathrm{Cr}(\mathrm{CO})_{3}$ complexes Acta Chim. Slov. 56246

36. Turker L 2014 Chromium tricarbonyl $\eta^{6}$-complexes of [3]cyclacene: A DFT study Z. Anorg. Allg. Chem. 640 1378

37. Turker L 2016 Chromium tricarbonyl $\eta^{6}$-complexes of (R)-[6]helicene: A DFT study J. J. Inorg. Chem. 1010

38. Laib S and Ouddai N 2015 Effect of haptotropic rearrangement on reactivity and biological activity in fluorenyl complexes: A DFT study J. Chem. Pharm. Res. 7 239

39. Mann B E 1986 Fluxionality of polyene and polyenyl metal complexes Chem. Soc. Rev. 15167

40. Dotz K H and Jahr H 2004 Tunable haptotropic metal migration in fused arenes: Towards organometallic switches Chem. Rec. 461

41. Feringa B L 2001 In Molecular Switches (Weinheim: Wiley $\mathrm{VCH}$ )
42. Bissell R A, Cordova E, Kaifer A E and Stoddart J F 1994 A chemically and electrochemically switchable molecular device Nature 369133

43. Nikitin k, Bothe C, Muller-Bunz H, Ortin $\mathrm{Y}$ and McGlichey J 2012 High and low rotational barriers in metal tricarbonyl complexes of 2- and 3-indenyl anthracenes and triptycenes: Rational design of molecular brakes Organometallics 316183

44. Rosillo M, Dominguez G and Perez-Castells J 2007 Chromium arene complexes in organic sysnthesis Chem. Soc. Rev. 361589

45. Frisch M J, Trucks G W, Schlegel H B, Scuseria G E, Robb M A, Cheeseman J R, Scalmani G, Barone V, Mennucci B, Petersson G A, Nakatsuji H, Caricato M, Li X, Hratchian H P, Izmaylov A F, Bloino J, Zheng G, Sonnenberg J L, Hada M, Ehara M, Toyota K, Fukuda R, Hasegawa J, Ishida M, Nakajima T, Honda Y, Kitao O, Nakai H, Vreven T, Montgomery J A, Peralta Jr J E, Ogliaro F, Bearpark M, Heyd J J, Brothers E, Kudin K N, Staroverov V N, Kobayashi R, Normand J, Raghavachari K, Rendell A, Burant J C, Iyengar S S, Tomasi J, Cossi M, Rega N, Millam J M, Klene M, Knox J E, Cross J B, Bakken V, Adamo C, Jaramillo J, Gomperts R, Stratmann R E, Yazyev O, Austin A J, Cammi R, Pomelli C, Ochterski J W, Martin R L, Morokuma K, Zakrzewski V G, Voth G A, Salvador P, Dannenberg J J, Dapprich S, Daniels A D, Farkas O, Foresman J B, Ortiz J V, Cioslowski J and Fox D J 2009 Gaussian 09 Revision A.1 (Wallingford CT: Gaussian Inc.)

46. Becke A D 1993 A new mixing of Hartree-Fock and local density-functional theories J. Chem. Phys. 981372

47. Lee C, Yang W and Parr R G 1988 Development of the Colle-Salvetti correlation-energy formula into a functional of the electron density Phys. Rev. B. 37785

48. Hariharan P C and Pople J A 1973 The influence of polarization functions on molecular orbital hydrogenation energies Theor. Chim. Acta. 28213

49. Hay P J and Wadt W R 1985 Ab initio effective core potentials for molecular calculations. Potentials for K to Au including the outermost core orbitals J. Chem. Phys. 82299

50. Fukui K 1981 The path of chemical-reactions: The IRC approach Acc. Chem. Res. 14363

51. Boys S F and Bernardi R 1979 The calculation of small molecular interactions by the differences of separate total energies. Some procedures with reduced errors $\mathrm{Mol}$. Phys. 19553

52. Foster J P and Weinhold F 1980 Natural bond orbitals $J$. Am. Chem. Soc. 1027211

53. Reed A D, Curtiss L A and Weinhold F 1988 Intermolecular interactions from a natural bond orbital, donor-acceptor viewpoint Chem. Rev. 88899

54. Glendening E D, Reed A E, Carpenter J E and Weinhold F 1988 NBO 3.1 Program Manual (Madison: Theoretical Chemistry Institute, University of Wisconsin)

55. Schleyer P v R, Maerker C, Dransfeld A, Jiao H and Hommes N J R v E 1996 Nucleus-independent chemical shifts: A simple and efficient aromaticity probe J. Am. Chem. Soc. 1186317

56. Wolinski K, Hinton J F and Pulay P 1990 Efficient implementation of the gauge independent atomic orbital 
method for NMR chemical shift calculations J. Am. Chem. Soc. 1128251

57. Grimme S, Antony J, Ehrlich S and Krieg H 2010 A consistent and accurate ab initio parameterization of density functional dispersion correction (DFT-D) for the 94 elements H-Pu J. Chem. Phys. 132154104
58. Grimme S, Ehrlich S and Goerigk L 2011 Effect of the damping function in dispersion corrected density functional theory J. Comp. Chem. 321456

59. Yang W and Parr R G 1985 Hardness, softness, and the Fukui function in the electronic theory of metals and catalysis Proc. Natl. Acad. Sci. USA 826723 